\title{
Conditioned word meaning and the interstimulus interval'
}

GARY J, COLES and THOMAS B. LEONARD, III, ${ }^{2}$ University of North Dakota, Grand Forks, N.D. 58201

Word meaning responses were established for groups having one of four interstimulus intervals (ISIs): $2 \mathrm{sec}$ backward, 1 sec backward, I sec forward, and 2 sec forward. There was no significant difference in the degree of conditioning shown by the four groups, and the acquisition of word meaning was due almost completely to the performance of Ss who were aware of the relations between CSs and USs. The appropriateness of labeling the acquisition of word meaning classical conditioning is questioned.

Assuming that portions of word meaning were composed of implicit responses, Staats \& Staats (1957) hypothesized that it should be possible to condition meaning to nonsense syllables by pairing them with words having a common meaning. Their procedure was to select words which had high factor loadings on dimensions of connotative meaning and pair them differentially with nonsense syllables. Experiments conducted by the Staats and by others have repeatedly demonstrated that nonsense syllables will acquire connotative and denotative meaning similar to that of the words with which they are paired. The process by which such acquisition occurs has commonly been assumed to be classical conditioning, since the procedure of repeatedly pairing syllables (CSs) and words similar in meaning (USs) is that of classical conditioning.

Is the procedural similarity of the Staats procedure to that of Pavlov an adequate criterion for deciding that word meaning is acquired by a classical conditioning process? The criterion for making such a decision should be that the learning process in question behaves as do other classical CRs, i.e., is related in similar ways to independent variables. Procedural similarity is an adequate criterion for the inclusion of a process within a category of processes only until evidence is accumulated to allow categorization on a better basis.

The question that should now be asked is whether variables known to be related to many classically conditioned responses in characteristic ways are also related to conditioned word meaning in similar ways. Little evidence is available for answering such a question. If factor loadings on evaluative meaning are thought of as indicating intensity of meaning, a US intensity effect may be inferred from the fact that CS syllables acquire meaning when paired with words having high factor loadings on either positive or negative evaluative meaning and not when paired with words having no such consistent factor loadings. Other parametric evidence would include the observations that the conditioning of meaning appears to be a positive function of the number of CS-syllable, US-word pairings and of the ratio of reinforcement used (Gerstein, 1961; Staats, Staats, \& Heard, 1960). These facts are characteristic of almost all forms of acquisition and do not justify the application of the classical conditioning model to explain a learning process having only methodological similarities to Pavlovian conditioning.

The present experiment was designed to determine the relationship between degree of conditioned word meaning and ISI, one of the most powerful variables affecting classically conditioned responses. Previous studies of classical conditioning have indicated that an ISI of approximately $.5 \mathrm{sec}$ is optimal for conditioning a finger flexion, an eyeblink, or the GSR (Beecroft, 1966). In addition, little or no conditioning occurs when the US precedes the CS. The effects of four ISIs, 1 and $2 \mathrm{sec}$ backward (B1 and B2 groups), and 1 and $2 \mathrm{sec}$ forward ( $\mathrm{F} 1$ and $\mathrm{F} 2$ groups), were investigated. An ISI of $1 \mathrm{sec}$ was investigated instead of $1 / 2 \mathrm{sec}$ because both CS and US were spoken by $E$, and an ISI of $1 / 2 \mathrm{sec}$ was too short to permit clear pronunciation. The effect of a less powerful variable, neutral and anxiety-producing instructions, was also investigated but is not reported.

\section{METHOD}

The Ss were introductory psychology students at the University of North Dakota who volunteered to participate in order to fulfill a course requirement. Ss were run in groups ranging in. size from 18 to 26 . There were $46,40,42$, and 36 Ss in Groups B2, B1, F1, and F2, respectively.

Materials used were similar to those used by Staats \& Staats (1957). An exception was that letters were used as CSs. In a previous study the evaluative meanings of six letters, $K, L, N$, $P, Q$, and $X$, were rated on five semantic differential scales by 15 Ss. The letters $X$ and $Q$ were found to have neutral and almost identical mean ratings, hence, were chosen as CSs for the present experiment.

The 108 words used as USs were those used in the original Staats \& Staats experiment (1957). The 18 US words with positive evaluative meaning were paired with $Q$, the 18 with negative evaluative meaning paired with $X$, and the 72 with neutral evaluative meaning with the other four letters, using the order of the Staats. Subsequent meaning change was measured by means of seven-point semantic differential rating scales. Four different scales were used, the bipolar terms on the ends of the scales being highly loaded on the evaluative dimension of meaning. The bipolar terms were pleasantunpleasant, good-bad, pretty-ugly, and like-dislike.

The general procedure was similar to that first used by Staats \& Staats (1957), except that both CS letters and US words were presented auditorily. The entire experimental procedure was prerecorded by E. ISIs were timed with a stopwatch and were within $.25 \mathrm{sec}$ of the appropriate interval.

In the recorded instructions $S$ were told that the experiment was concerned with the effectiveness of two different forms of learning and the interfering effect that hearing letters and words together has upon the retention of the words. They were then presented with the 108 letter-word pairs with an intertrial interval of $10 \mathrm{sec}$. Immediately following the conditioning trials, Ss were told that it was necessary to learn if they had preferences for any of the interfering letters and were given the semantic differential scales for all six letters. After a number of other tasks designed to increase the credibility of the proceedings, Ss completed a questionnaire which was used to assess whether or not they were aware of the fact that positive words had been paired with $Q$ and negative words with $X$.

\section{RESULTS}

For each $S$ the mean rating over all semantic differential scales was computed for the letters $Q$ and $X$. The difference between the two mean ratings was $S$ 's differential conditioning score, with a positive difference indicating the expected conditioned meaning. The differential conditioning means of the groups were: 1.51 for $\mathrm{B} 2,2.09$ for $\mathrm{B} 1,1.58$ for $\mathrm{F} 1$, and 2.83 for $F 2$. T-tests showed that each of the four means was significantly greater than zero $(p<.05)$, indicating that all groups did show the expected learning.

An unweighted means analysis of variance was performed to determine whether the four ISI treatment conditions differed significantly. The resultant $F$ was not significant $(F=2.19$, $\mathrm{p}<.10$ ).

The mean differential conditioning score for the $86 \mathrm{Ss}$ receiving backward conditioning was 1.78 , and the mean for the 78 Ss receiving forward conditioning was 2.16 . The 
difference between means was not significant $(t=.90$. $\mathrm{df}=162$ ), indicating no significant superiority of the forward conditioning groups.

Mean differential conditioning scores were also computed for those Ss who reported no awareness of the relationship between the letters $Q$ and $X$ and the types of words paired with them. The numbers of nonaware Ss were 24, 17, 24, and 21 for Groups B2, B1, F1, and F2, respectively. A $x^{2}$ test showed that the numbers of Ss showing awareness in the four groups did not differ significantly from values expected by chance. The mean differential conditioning scores were .27 for Group B2, -.43 for B1, .24 for F1, and 1.10 for F2. The only mean significantly greater than zero was that of the $F 2$ group $(t=4.4, d f=20, p<.01)$.

\section{DISCUSSION}

The results showed (1) that all groups, forward and backward, exhibited differential conditioning significantly greater than zero, (2) that there were no significant differences among the differential conditioning means for the four ISI groups, (3) that the difference between forward and backward treatment groups was not significant, and (4) that the conditioning effect tended to disappear when aware Ss were excluded. These results are not consistent with those found for most classically conditioned responses. Backward procedures usually produce no conditioning, and ISIs of greater than $1 \mathrm{sec}$ usually produce minimal conditioning. More important, the ISI condition in the present experiment which was most similar to the optimal ISI for classical conditioning, i.e.. Fl, did not lead to the greatest degree of differential conditioning.

The major conclusion to be drawn from the results is that the ISI function for conditioned word meaning does not resemble the function observed for classically conditioned responses such as the GSR, the eyeblink, and flexion responses. If one demands that a response behave as other classically conditioned responses when powerful variables such as ISI are manipulated in order to be classified as a classically conditioned response, then conditioned word meaning fails to meet the test. It has not been demonstrated that variables affecting classically conditioned responses in characteristic ways affect conditioned word meaning in similar ways, excepting the effects of variables such as percentage of reinforcement and number of trials, which affect almost all learned responses, classically conditioned or not, in similar ways. In short, the characteristic functions relating level of classical conditioning to kevels of independent variables have not been shown to exist for word meaning responses.

That word meaning is not classically conditioned is also indicated in the present study by the fact that the conditioning was due almost entirely to the scores of Ss who were aware of the relation between the letters and the word classes used. Only for Group F? was the degree of conditioning significantly different from zero when aware Ss were eliminated. This finding replicates that of other recent investigations (Cohen, 1964: Hare. 1964: Insko \& Oakes, 1966: Pavio, 1964) and is a further indication that the learning process is probably not classical conditioning. Classical CRs are generally defined as nonvoluntary responses, but word meaning responses appear to occur only when $S$ is aware of the relation between CS material and US material.

On two counts, then. the labeling of word meaning responses as classically conditioned responses appears unjustified. First, in contrast to classically conditioned responses, the acquisition of word meaning does not depend on the ISI used and has not been shown to be related to other independent variables in ways similar to classical CRs. Second, in contrast to classically conditioned responses the occurrence of conditioned word meaning responses depends on S's awareness of the relation between CS letters and US words.

\section{REFERENCES}

BEECROFT, R. S. Classical Conditioning. Goleta, Calitornia: Psychonomic Press, 1966.

COHEN, B. H. Role of awareness in meaning established by classicil conditioning. Journal of Experimental Psychology, 1964, 67, 373-37\%.

GERSTEIN, A. I. The effect of reinforcement schedules on meaning generalization and on awareness of the purpose of the experiment. Journal of Personality, 1961, 29, 350-362.

HARE, R. D. Cognitive factors in transfer of meaning. Psychological Reports, 1964, 15, 199-206.

INSKO, C. A., \& OAKES, W. F. Awareness and the conditioning of attitudes. Journal of Personality, 1966, 4, 487-496.

PAVIO, A. Generalization of verbally conditioned meaning from symbol to referent. Canadian Journal of Psychology, 1964, 18, 146-155.

STAATS, C., \& STAATS, A. W. Meaning established by classical conditioning. Journal of Experimental Psychology, 1957, 54. 74-80.

STAATS, A. W., STAATS, C., \& HEARD, W. G. Language conditioning of meaning to meaning using a semantic generalization paradigm. Journal of Experimental Psychology, 1959, 57, 187-191.

STAATS, A. W., STAATS, C., \& HEARD, W. G. Attitude development and ratio of reinforcement. Sociometry, 1960, 23, 338-350. NOTES

1. This investigation was supported, in part, by a Faculty Research Award from the University of North Dakota to the second author.

2. Now at the University of Mississippi.

\section{(Contintued from page 59)}

The results are quite clear: For word stimuli there are warm-up effects in the associative stage of paired-associate learning but not in the response-learning stage of the same task. This suggests that the finding of previous investigators which indicates the presence of a warm-up effect in paired-associate learning may be largely attributed to the warming up that occurs in the associative stage of that task. It appears that warm-up effects are largely localized in the associative stage of paired-associate learning.

The similarity between performance on response learning in the current experiment and free recall of unrelated words in the Raffetto \& Koeppel study (1968) is quite striking. In both cases no significant increase could be found in performance from list to list, yet in both experiments improvement over trials occurred within lists. This close resemblance of findings supports the assumption that the processes which are operative in the response-learning phase of paired-associate tasks roughly correspond to the processes involved in free recall.

\section{REFERENCES}

MURDOCK, B. B., JR. The immediate retention of unrelated words. Journal of Experimental Psychology, 1960, 60, 222-234.

RAFFETTO, A. M., \& KOEPPEL, J. C. Warmup effects in free recall. Psychonomic Science, 1968, 12, 397-398.

THORNDIKE, E. L., \& LORGE, 1. The teacher's word book of 30,000 words. New York: Teacher's College, Columbia University, 1944.

THUNE, L. E. The effect of different types of preliminary activities on subsequent learning of paired-associate material. Journal of Experimental Psychology, 1950, 40, 423-438.

UNDERWOOD, B. J., \& SCHULZ, R. W. Meaningfulness and t'erbal learning. Philadelphia: Lippincott. 1960. 